\title{
The attraction of uncertainty: Interactions between skill and levels of uncertainty in market-entry games
}

\author{
Natalia Karelaia $\cdot$ Robin M. Hogarth
}

(C) Springer Science+Business Media, LLC 2010

\begin{abstract}
The experimental market entry paradigm has been used to illuminate the role of self-assessed skill in risk taking. Specifically, success only accompanies entry if a participant is one of the better ranked entrants on the skill criterion. We investigate what happens when participants face an additional source of uncertainty that perturbs relative skill rankings. Interestingly, this has asymmetric effects. On average, chances of success are increased for those with low rankings but decreased for those with high rankings. Thus, we predicted that the additional uncertainty would lead to more entry by the former but less by the latter. Our data supported the first prediction but, for those with high skill rankings, the existence of additional uncertainty made little difference. Finally, although we observed "excess entry" (i.e., too many participants entered markets), this could not be attributed to overconfidence. We conclude by contrasting our results with others in the literature.
\end{abstract}

Keywords Skill $\cdot$ Uncertainty $\cdot$ Overconfidence $\cdot$ Tournaments $\cdot$ Competition $\cdot$ Risk taking $\cdot$ Gender differences

JEL classification $\mathrm{C} 91 \cdot \mathrm{D} 03 \cdot \mathrm{D} 81$

\footnotetext{
The authors appreciate the insightful comments on earlier versions of this paper by Daniel Read and Don Moore as well as comments by seminar participants at the London Business School, the University of Trento, and Universitat Pompeu Fabra. They also thank Roger Rodrigo and Augusto Rupérez-Micola for help in conducting the experiments. This research was financed partially by grants from the Swiss National Science Foundation and the INSEAD Alumni Fund (Karelaia), and the Spanish Ministerio de Ciencia y Innovación (Hogarth), grant SEJ2006-14098.
}

N. Karelaia $(\bowtie)$

INSEAD, Boulevard de Constance, Fontainebleau 77305, France

e-mail: natalia.karelaia@insead.edu

R. M. Hogarth

ICREA \& Universitat Pompeu Fabra, Barcelona, Spain

e-mail: robin.hogarth@upf.edu 
It is common for people to compete for access to limited resources. Consider, for example, applications by researchers for grants, attempts to obtain positions in large organizations or public office, and decisions by potential entrepreneurs to enter new markets. These situations typically share four characteristics: (1) a limited number of resources can be given to only $k$ of $N$ agents where $k<N$; (2) each agent has to decide independently whether or not to enter the competition; (3) agents who enter the competition are ranked according to a criterion of skill and the resources are allocated to those with the $k$ highest ranks. The unsuccessful entrants incur additional costs; (4) prior to deciding, each agent receives a signal that is probabilistically related to his or her score on the skill ranking criterion.

Perhaps the best known example of this paradigm in the economic literature is the work by Camerer and Lovallo (1999) who used it to model entrepreneurial entry. Their focus was on possible effects of overconfidence which they tested by comparing responses (i.e., entry decisions) between conditions where entrants were ranked at random as opposed to their knowledge measured by a test. Camerer and Lovallo noted higher entry rates when ranks were established on the basis of tests (i.e., skill) as opposed to random orderings, a result they interpreted as indicating overconfidence. ${ }^{1}$ Using a similar experimental design, Moore and Cain (2007) varied test difficulty and found higher entry rates for easy as opposed to hard tests.

These results demonstrate that the experimental market paradigm is a rich source of insight about the interplay between risky decision making and self-assessed skills. And yet, we contend that the work reported to date has been limited by failing to consider a wider range of sources of uncertainty. In particular, in the paradigm outlined above, there are only two such sources: (1) imperfection in the validity of the signals that agents receive about their skills; and (2) uncertainty about the actions of the other agents (i.e., whether they will or will not enter the competition).

The outcomes of naturally occurring markets, however, are typically characterized by many sources of uncertainty. A potential entrepreneur, for example, should not only be concerned about the level of her skills relative to competitors but also the other uncertainties inherent in economic conditions. What will be the demand for the new product? Will there be a general economic downturn? Will there be unanticipated surprises, e.g., a presently unknown competitor introduces a technologically superior product? And so on. Clearly, the potential effects of such random factors are important and should be modeled.

Our goal in this paper is to expand the market entry paradigm by investigating what happens when uncertainty plays a more important role in determining outcomes. Specifically, what happens when, in addition to both noise in assessing own skill and uncertainty concerning the actions of others, agents learn that the skill rankings have been perturbed by an explicit random factor? For example, imagine that the economy has taken a turn for the worse and that this shock changes the skill set necessary to be successful in the new market conditions.

From the viewpoint of the agents, the effect of introducing an additional source of uncertainty is to reduce the validity of the signal they receive about their potential

\footnotetext{
${ }^{1}$ Incidentally, whether Camerer and Lovallo's (1999) results really demonstrate overconfidence can be questioned (Benoit and Dubra 2009; Hogarth and Karelaia 2009). However, this is not the goal of the present paper.
} 
performance. Absent the explicit random factor, this was imperfect; with the random factor, it becomes even more imperfect. Therefore, it seems reasonable to hypothesize that agents will react to the additional uncertainty by being less likely to enter the competition, i.e., because the additional noise reduces the value of their information about their skill. Indeed, one can interpret the results of Camerer and Lovallo (1999) from precisely this perspective. That is, agents entered competitions less when signals had zero validity (i.e., when ranks were established at random) as opposed to when they were based on test scores. Moreover, in Moore and Cain's (2007) study — where agents entered markets more frequently when tests were easy as opposed to hard-signal validity (the correlation between agents' true and estimated scores on the skill criterion) was greater in the easy as opposed to the hard task (D. Moore, personal communication, July 2007).

One might thus expect a general tendency for agents to enter competitions less when signals about skill become less valid. However, is this true of all agents? In particular, how does the introduction of additional uncertainty affect agents who differ in beliefs about their skill levels, e.g., high versus low? As we show, there is an intriguing asymmetry induced by the competitive structure of the market entry game.

Recall that what matters is whether an agent's skill ranking is among the first $k$ of those who actually enter the market. Thus, an agent whose true ability merits a place in the first $k$ can only be hurt by the introduction of the additional source of uncertainty (i.e., demoted below the $k^{\text {th }}$ position) but not helped. However, an agent whose true ability does not merit a place in the first $k$ can be helped by the random perturbation (i.e., promoted into the top $k$ positions) but not hurt. This reasoning therefore leads to an alternative hypothesis. With the introduction of additional uncertainty, agents who believe that they have relatively high scores on the criterion will enter competition at a lower rate than in its absence. On the contrary, agents who believe they have low scores will enter at a higher rate when uncertainty is increased. It is, after all, the only way they can succeed.

Our work also speaks to the literature on the strategic choice of variability in tournaments with a fixed proportion of winners. In this paradigm, agents select between risky options that differ in the variability of outcomes but not in their means. The intriguing outcome of this set-up is that the options with more variable outcomes have greater probability of exceeding certain thresholds. Thus, it could be rational for agents to choose higher levels of uncertainty. For example, Gaba et al. (2004) showed analytically that when the proportion of winners is less (greater) than $50 \%$, by choosing a riskier (safer) performance distribution an agent improves her probability of winning the tournament. Indeed, Gaba and Kalra (1999) provide evidence supporting this conclusion in experiments simulating how sales representatives react to incentives in the form of a competition (e.g., bonuses are only paid to the best 3 of 10 representatives).

The paradigm of Gaba et al. (2004), however, differs from ours in two ways. First, their agents choose between actions implying different levels of uncertainty as opposed to between a safe option (not entering the market) and an outcome subject to uncertainty (with no control over the level experienced). Second, Gaba et al. (2004) do not differentiate between low- and high-skill individuals. Similarly, in the experiments reported in Gaba and Kalra (1999), performance does not depend on skill, but only on a value drawn from the distribution that each participant chooses. 
In a further paper, Tsetlin et al. (2004) consider multiple-round tournaments where cumulative performance determines the winners. They distinguish between contestants in "weak" and "strong" positions which can be defined, for example, by performance in the last round of the contest. Their results show that in order to maximize the probability of winning the contest, weak contestants should maximize variability, while those in a strong position should minimize variability. For example, mutual fund mangers who lag behind their competitors in a given period might increase the riskiness of their portfolio in order to outperform competitors in the next period (Chevalier and Ellison 1997).

Similarly, Degeorge et al. (2004) show that when agents have private information regarding their quality and are concerned about their reputation, good agents will choose low levels of risk to enhance their reputation in the market, while bad agents will choose high levels of risk. They further illustrate their theoretical results with empirical evidence that firms of higher "quality" have less variable performance. Our paper differs from this literature in that we provide experimental evidence that, in tournaments, risk taking in the face of augmented uncertainty is moderated by skill level.

As noted, when entering a market with a limited number of winners, $k$, agents need to estimate their chances of being ranked among the $k$ best entrants and, yet, they only receive an imperfect signal that informs them about their absolute score on the criterion and not their relative ranking as such. An interesting issue therefore also centers on how accurate agents are in estimating both their criterion scores and relative rankings as well as what might affect this. For example, there is an extensive literature that demonstrates that people over-(under)estimate their abilities in hard (easy) tasks and simultaneously under-(over)place themselves (i.e., relative to others) (Moore and Healy 2008. However, see also Grieco and Hogarth 2009). In our work, we did not manipulate the difficulty of the task that determines the signal, and thus have no hypothesis concerning the effects of confidence.

The role of gender has also often been highlighted as affecting differential degrees of confidence and attitudes toward risk (Croson and Gneezy 2009). It is generally claimed, for example, that men are more overconfident than women (Barber and Odean 2001) and that women are both more risk averse than men (Byrnes et al. 1999) and less willing to place themselves in competitive situations (Niederle and Vesterlund 2007). Does gender moderate the hypothesized relations between uncertainty and self-assessed skill?

The rest of this paper is organized as follows. In the next section, we describe the experiment we conducted to test the hypotheses outlined above. Specifically, we used a market entry game involving within-subject conditions to control for individual differences. In one condition, participants were ranked by their skill and payoffs were fully determined by relative skill. In the other, skill rankings were subjected to individual random adjustments such that the relation between relative skill and payoffs was imperfect. Moreover, participants were made aware of this fact.

Our results, reported in the subsequent section, showed that low-ability participants (i.e., those who performed relatively poorly on the test) entered competition more when the level of uncertainty determining payoffs increased. However, at the same time, we did not find much evidence that participants with high test scores were less willing to enter competition. The high-ability participants, it seems, still hoped to achieve good outcomes whatever the level of uncertainty. 
Parenthetically, our data also show that participants tended to attribute success to their skill, while luck was more likely to be blamed for failures.

Overall, there was evidence of excess entry in that mean group profit was negative in most rounds as more participants entered the markets than should have. At the same time, we also found accurate assessments of numbers of entrants and no effect of initial confidence. Since the outcomes of market entry decisions in naturally occurring environments inevitably involve elements of both skill and uncertainty, our results contribute to explaining why low-skill participants still enter markets and, for the most part, fail. Finally, the only gender effects we found in our data were small and statistically insignificant.

The paper concludes by contrasting our results with others in the literature.

\section{Experiment}

Participants and sessions Participants were recruited through invitations sent to the members of the database system of the Leex laboratory of Universitat Pompeu Fabra and the experiment was conducted on computers in the laboratory using the z-Tree software (Fischbacher 1999). No participant took part in more than one session. Upon arrival participants were randomly assigned to seats. They were identified by code numbers only. Each participant had an individual printed copy of the instructions. Instructions also appeared on the screens. In addition, one experimenter read the instructions aloud. All questions were answered in private. Sessions lasted about one hour. There were six separate sessions, each with fifteen participants.

Procedure Participants were informed that they were being given a credit of $15 €$ at the beginning of the experiment, and that at the end, their net earnings would be added to (or deducted from) the $15 €$. Moreover, their net earnings would depend on both their choices and the choices of other participants taking part in the same session. Participants were further told that the study was conducted anonymously and that their individual choices would not be known to other participants. Table 1 summarizes the experimental procedure for one of the experimental conditions explained in detail below.

There were two parts to the experiment. The first involved ten problems of multiplying two 2-digit numbers. Participants could use a pen and scratch paper. They were paid $0.50 €$ for each correct answer and informed that the more questions they got correct, and the faster they were, the easier it would be for them to earn more money in the second part of the experiment. The ten problems appeared one by one on the screen. Participants had $30 \mathrm{~s}$ to solve each problem. If no answer was provided within $30 \mathrm{~s}$, the question was counted as "incorrect" and the next problem appeared automatically. After answering ten problems, participants were asked how many problems they thought they had solved correctly and how many of the fourteen other participants in the room they believed did better than them (i.e., answered more questions correctly and/or were faster). At the end of the experiment, they were paid $0.50 €$ for each correct estimate. Feedback on the multiplication test was not given until the end of the experiment. 
Table 1 Summary of experimental procedure

Task 1

10 multiplication problems $(0.50 €$ for each correct answer)

"How many correct?"

"How many of the 14 others did better than you?"

Task 2

Market entry game

1. Quiz to check understanding

2. First 6 rounds (no chance component)

For each round:

a. Forecast number of entrants $(0.50 €$ for accurate forecast)

b. Decide to enter or not

c. Feedback: number of entrants and individual payoff

3. After first 6 rounds

"How risky were the rounds?"

4. Second 6 rounds (chance component)

For each round:

a. Forecast number of entrants $(0.50 €$ for accurate forecast)

b. Decide to enter or not

c. Feedback: number of entrants and individual payoff

d. "How lucky in round?" \& "How fair was payoff?"

5. After second 6 rounds:

"How risky were the rounds?"

"How fair were rounds overall?"

"What role of luck in payoffs?"

Feedback on performance in Task 1 (multiplication test)

Completion of Rotter's (1966) I-E test

Participants remunerated individually

The procedure is shown for the experimental condition for which there was no explicit chance condition in the first six rounds but there was in the second six rounds.

The second part of the experiment was a market entry game involving an experimental market with a capacity of five entrants and a total payoff to be divided among successful entrants of $25 €$. Each participant had to decide privately whether or not to enter. If they decided to stay out, the additional payoff was zero. If they decided to enter, the payoffs were determined by the number of entrants and the results of the multiplication test. If the number of entrants was five or less, the $25 €$ was divided equally among the entrants. If more than five participants decided to enter the competition, all entrants were ranked according to the number of problems solved correctly in the multiplication task. Time taken to complete the test was used to break ties. The five best entrants earned $5 €$ each and the others lost $10 €$ each.

Before the first entry decision was made, participants were informed that there would be a total of twelve similar rounds. At the end of the experiment, four of the twelve rounds were chosen randomly by throwing a die. Final payoffs for the market entry game were determined by the mean of individual payoffs in these four rounds. 
Participants were informed in advance about how the final payoffs would be determined.

Before the first round, four questions were administered to make sure that everyone understood the rules of the game. Participants were given three attempts to answer each question. Eighteen participants failed to provide a correct answer to one or two questions. We analyzed the data both with and without these participants and found that excluding these 18 participants did not change results significantly. We therefore report below the analyses of all data.

At the beginning of each round, participants were asked to forecast how many entrants would enter (including themselves) in the round. Accurate forecasts were rewarded with $0.50 €$. Participants then decided individually whether or not to enter the competition. Post-decision feedback for each round was the number of entrants and the participant's individual payoff. After the first six and the last six rounds participants were asked to indicate on an 11-point scale how risky these rounds were in their opinion ( $0=$ "not risky at all" and $10=$ "extremely risky").

For the last six rounds, the procedure for determining the performance ranking was changed by including an explicit random component. Participants were told about the changes in the rules of the game immediately before the block of the modified rounds. While we recognize that there are different ways to add more uncertainty, we chose the following. At the beginning of each round, individual random parameters were drawn from a uniform distribution. There were seven possible outcomes of this draw: an improvement of the position in the original ranking by three places, two places, and one place; a worsening of the position in the ranking by three places, two places, and one place; and no change of the original position. The process of generating these parameters was described to participants using the analogy of an urn containing seven balls of different colors. In each modified round, after receiving performance feedback, participants were additionally asked to indicate on 11-point scales how lucky they thought they had been in the round $(0=$ "not at all" and $10=$ "extremely lucky") and how fair they thought their payoff was in the round ( $0=$ "not at all" and $10=$ "extremely fair"). Finally, after the block of six modified rounds, participants additionally indicated on 11-point scales how fair they thought their result was overall in these rounds $(0=$ "not at all" and 10 = "extremely fair") and what role, in their opinion, chance played in determining their payoffs in these six rounds $(0=$ "chance has not played any role"; and 10 = "chance has been decisive").

After all twelve rounds, participants received feedback on the number of correct answers and their total time spent on the multiplication test, indicated their age and gender, and answered 29 questions of the internal-external(IE)-scale questionnaire (Rotter 1966) that purports to measure individual locus of control. Locus of control refers to the extent to which individuals believe that they can control events. Individuals with a high internal locus of control (a low score on the Rotter scale) believe that their actions mainly determine their outcomes whereas those at the other extreme believe that they have little control over what happens to them.

Finally, a 12-faced die was thrown to determine the four rounds to be used to calculate total payoffs and the information on individual total payoffs appeared on the participants' screens. Participants were paid privately one-by-one at the end of the experimental session. 
Design The experimental design included two within-subject variables and two between-subject variables. The within-subject variables were round number and whether a randomly generated random component was (chance rounds) or was not used (baseline rounds) to determine performance ranking in a given round. The between-subject variables were the level of chance and order of rounds. In four sessions (of eight), the random component was enlarged. In these sessions, the position in the original ranking could increase or decrease by nine, six, or three places (vs. three, two, one place in the other chance sessions). We refer to these sessions as the big chance condition and to the other sessions as the small chance condition. As to the order of rounds, baseline rounds preceded chance rounds in four sessions, and chance rounds preceded baseline rounds in the other four sessions. In summary, there were four between-subject conditions: (1) baseline-small chance, (2) small chance — baseline, (3) baseline - big chance, and (4) big chance - baseline.

Main hypotheses The main question we pose is how adding noise to agents' evaluations affects their willingness to enter competitive situations. We hypothesize that there is a difference between the responses of low-skill and high-skill participants.

Hypothesis 1: Participants who score low on the test will enter the competition more in the chance than in the baseline condition.

Hypothesis 2: Participants who score high on the test will enter the competition less in the chance than in the baseline condition.

To illuminate how the random perturbation of rankings in the chance conditions would affect individual ranks, we ran simulations for each value of initial rank (from 1 to 15). The results are shown in the upper and lower parts of Fig. 1 for small and big chance, respectively. The simulations were done over 10,000 trials and show, for each rank, the distribution of ranks that would obtain. (Ties were resolved randomly). Thus, with small chance, someone ranked 1st would rarely fall below the 5th rank whereas someone ranked 5th would have a good chance of losing by falling below that position. Similarly, participants with ranks worse than the 10th position would rarely succeed (i.e., be better than 6th) while those in the middle ranks (e.g., 6th through 9th) start to have chances of success that would have been denied in the absence of chance. With large chance, the simulations show the same kinds of trends except that the distributions are naturally much flatter.

Equilibrium predictions Assuming risk neutrality and no private information about the probability of success on entry, there are multiple pure-strategy Nash equilibria with seven players (47\%) entering a market that has a capacity of five. Provided that players cannot coordinate, there is a mixed-strategy equilibrium in which each riskneutral player (without private information about the probability of success on entry) enters with probability of $53 \%$. This corresponds to 7.9 players (out of 15$)^{2}$. Detailed calculations are presented in the Appendix.

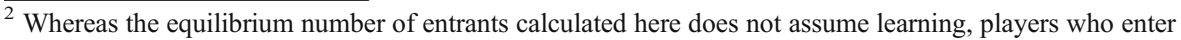
the market receive feedback and thus do have opportunities to learn across rounds. The equilibrium number of entrants is thus appropriate for the first round (no opportunities for learning) and serves as a nolearning benchmark for the others.
} 


\section{Small Chance}

initial rank1 initial rank2 initial rank3 initial rank4 initial rank5
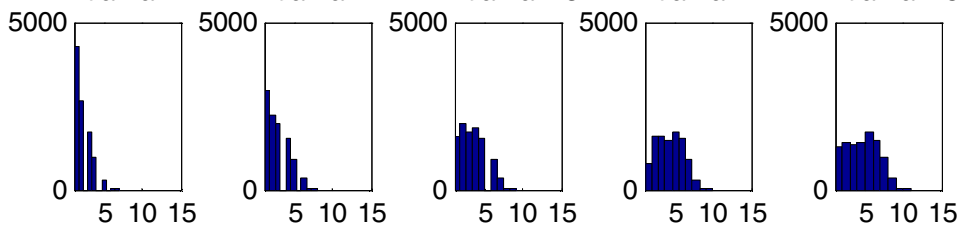

initial rank6 initial rank7
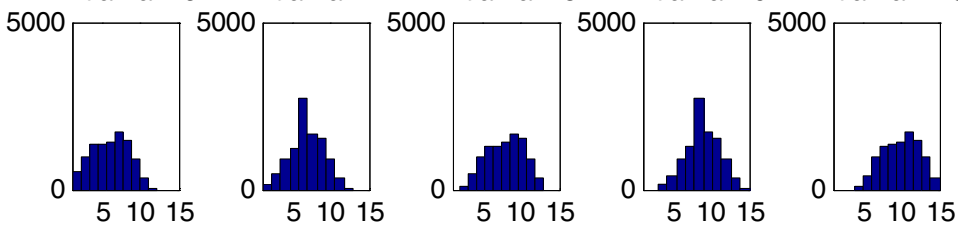

initial rank11 initial rank12
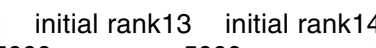

4 initial rank15
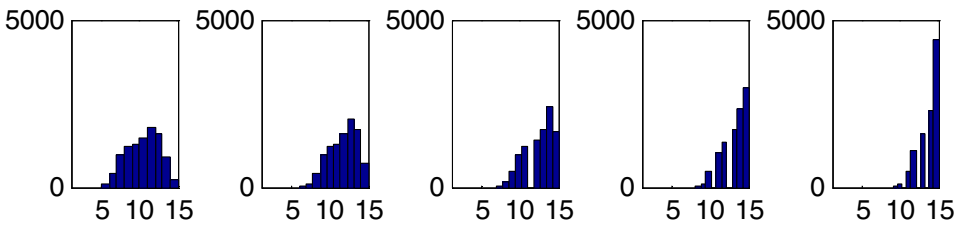

Big chance

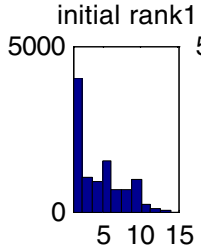

initial rank2
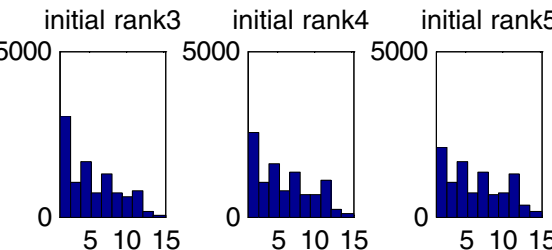

initial rank6 initial rank7
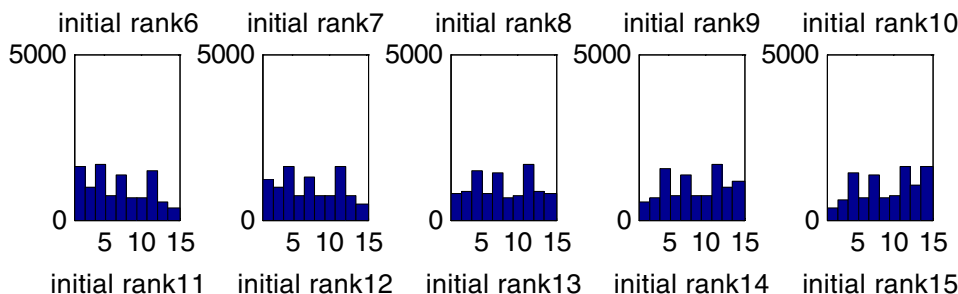

initial rank15
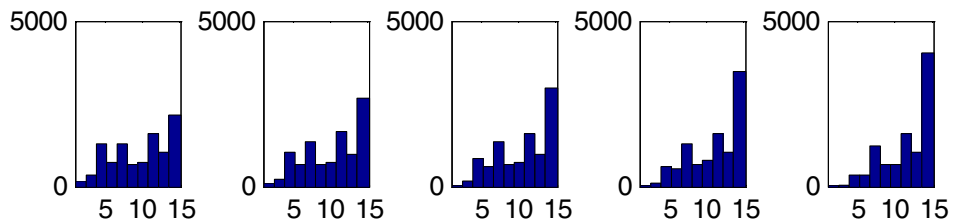

Fig. 1 Effects of chance on relative rankings 
If all players know their relative performance on the test, then only the top five players (33\% of all potential entrants) enter. However, if players have imperfect information about their test performance, the equilibrium number of entrants will be higher when players overestimate their probabilities of success and lower when the probability of success is underestimated. This idea is developed further in the Appendix.

We do not make any specific assumption about participants' risk preferences but control for it within-subject since all participants took part in both baseline and chance conditions (cf., Camerer and Lovallo 1999; Moore and Cain 2007). Our primary measure of interest is within-subject differences in behavior between the baseline and chance conditions.

\section{Results}

Of the 120 participants, 57 were male. Participants were between 18 and 36 years of age, 21 on average. Total earnings per participant were between $5.50 €$ and $25.90 €$ with a mean of $18.23 €$ and median of $18.63 €$. The mean number of correctly solved problems in the multiplication test was 8.1 (out of 10), the median was 9.0. There were on average nine entrants per round. Mean group payoff in the market entry game across all sessions was $-17 €$. Fig. 2 details the distribution of group payoffs.

\subsection{The effect of increasing uncertainty}

Our main question is whether adding the random component to the evaluation procedure affected participants' decisions to enter the competition and whether the effect was different for participants who scored low as opposed to high on the test. The data support the following main results:

Result 1: Low-skill participants enter competition more when the outcomedetermining procedure is noisier.

Result 2: High-skill participants enter competition somewhat less when the outcome-determining procedure is noisier.

Result 3: High-skill participants are less sensitive to changes in the outcomedetermining procedure than low-skill participants.

Statistical approach To determine how entry decisions depend on increasing uncertainty, we estimated several logit models of entry. We coded "entry" as 1 if the participant decided to enter competition in a given round and as 0 otherwise. We used a random-effects (subject-specific) specification in these models to control for the possibility of unobserved individual heterogeneity and to account for the within-subject manipulation of the chance factor, as well as multiple rounds in each condition (i.e., the fact that we have repeated observations on the same individuals). ${ }^{3}$ Robust standard errors were calculated to further account for clustering on individuals. This

\footnotetext{
${ }^{3}$ Population-averaged (marginal) specifications that do not account for the heterogeneity and test the effects of the chance manipulation on the average person yield qualitatively the same results (not reported here).
} 


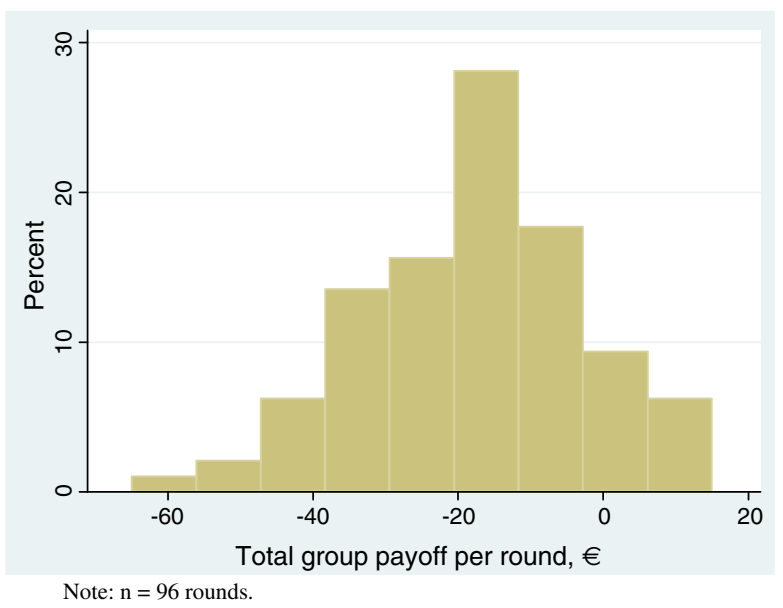

Fig. 2 Histogram of group payoffs

specification allows for the inclusion of time-invariant covariates (e.g., skill, gender, order of conditions), whereas the alternative of using fixed-effects models does not.

We estimated the following basic model:

$$
\operatorname{logit} \mathrm{P}\left(\text { Entry }_{i j}=1 \mid u_{i}\right)=\beta_{0}+\beta_{1} \text { chance }_{j}+u_{i}+e_{i j},
$$

where "chance" is an indicator variable for the augmented uncertainty rounds. The random intercept $u_{i}$ is constant through all rounds and can be thought of as a participant's propensity to enter competition (across all rounds) that is independent of the effects of the model covariates. Finally, $\beta_{0}$ is the log odds of entry of a "typical" participant (with random effect $u_{i}=0$ ), and $e_{i j}$ is the occasion-specific error.

To test whether the effect of chance was asymmetric with respect to skill, we estimated an augmented model, with skill and the interaction between skill and chance as additional predictors:

$$
\operatorname{logit} \mathrm{P}\left(\text { Entry }_{i j}=1 \mid u_{i}\right)=\beta_{0}+\beta_{1} \text { chance }_{j}+\beta_{2} \text { skill }_{i}+\beta_{3} \text { skill }_{i} \text { chance }_{j}+u_{i}+e_{i j},
$$

where "skill" is a participant's position in the ranking. Finally, we also estimated similar models with additional subject- and subject-round level covariates (e.g., gender, forecasted number of entrants).

Outcomes The results for the random effect models are reported in Table 2. Model 1 reports the basic specification with "chance" as the only predictor of entry. Model 2 includes the effects of the augmented chance component ("chance"), skill ("rank"), and the interaction term. Model 3 includes additional predictors: the big chance condition, gender (both indicator variables), the IE score, and the forecasted number of entrants. It also controls for possible order effects (an indicator variable). Model 4 includes in addition the entry decision made in the previous round and the payoff earned in that round. (It thus excludes the first round for which no lagged data are available.) Finally, model 5 tests the effects of confidence (measured at the beginning of the market-entry game) on entry and also includes subject-specific 


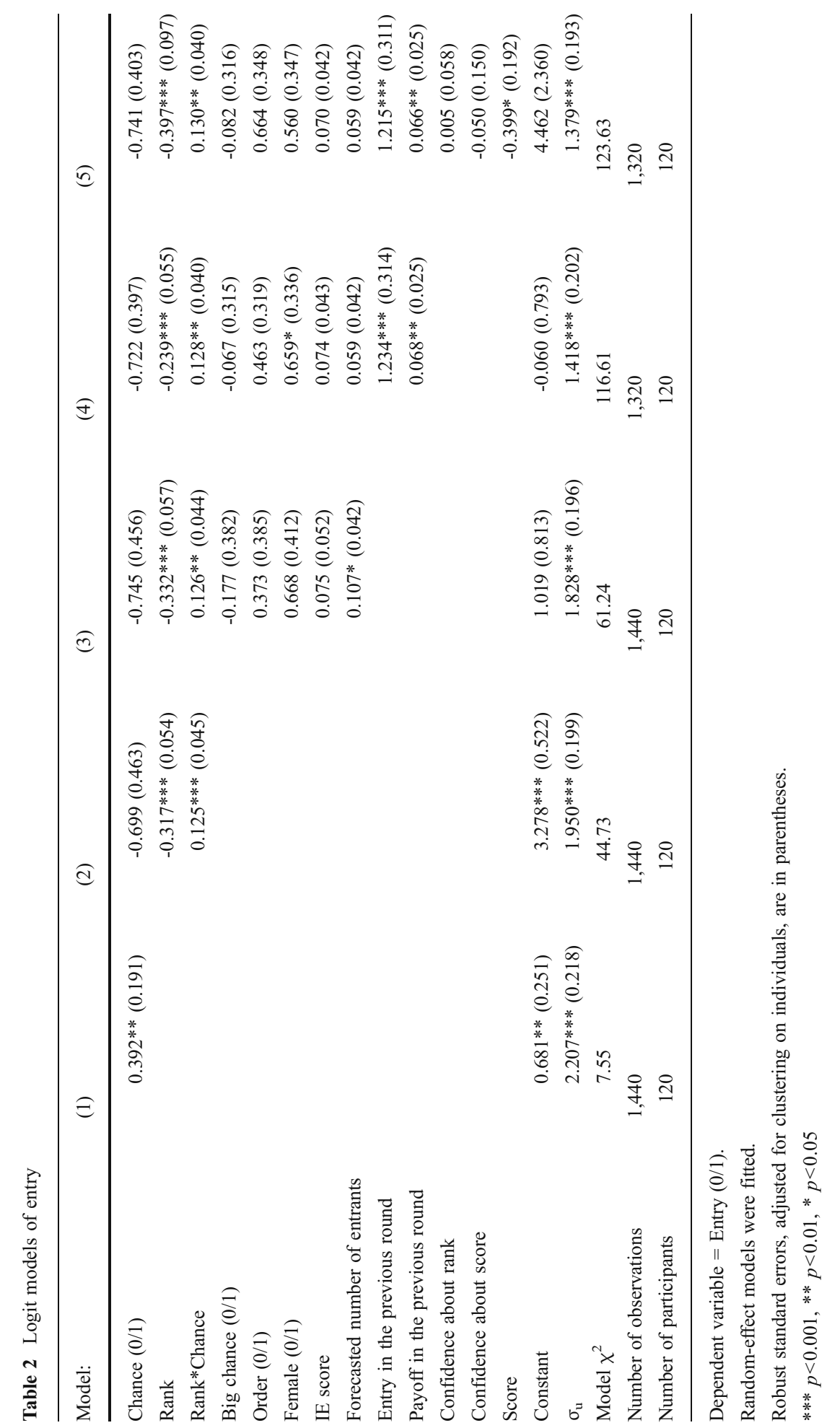


measures of confidence about score, confidence about rank, and actual score. (We comment on the results of this model further below.)

In the basic model 1, the effect of chance is positive which suggests that chance encouraged entry. The probability of entry was 8.1 percentage points higher in the chance as compared to the baseline condition (the marginal effect is computed assuming the random intercept is zero). Descriptive data confirm the result of the logit model: on average, there were 9.6 entrants in the chance rounds as compared to 8.8 entrants in the baseline rounds.

Model 2 tests for the asymmetric effect of chance on participants with different levels of skill and, to this end, includes main and interaction effects of chance and skill. Both effects need to be considered to assess the net effects of chance and skill on entry. The interaction effect is positive which suggests that the negative main effect of chance is offset for many players, the net effect of chance being positive for ranks beyond 5. Similarly, in the chance condition, the positive interaction term offsets the negative main effect of rank on entry. ${ }^{4}$ The interaction effect is positive and significant throughout models $2-5$ that include additional predictors. Moreover, the inclusion of additional predictors has little effect on the magnitude of the estimated coefficients of chance, skill, and the interaction between chance and skill.

The net effects of chance and skill on the probability of entry are plotted in Fig. 3. The plot shows the probability of entry - as predicted by model $3^{5}$ - as a function of skill, separately for the baseline and chance conditions. The probability of entry includes the effect of the interaction between chance and skill and the effects of all other variables included in model 3 (estimated at their mean level). For constructing the plots of marginal effects, it is assumed that the subject-specific random factors $u_{\mathrm{i}}=0$.

The slopes of the lines in Fig. 3 are decreasing which indicates that the probability of entry is lower for higher rank (i.e., lower skill). However, the slope of the lines corresponding to the chance condition is not as steep as that of the baseline condition. That is, low-skill participants enter the market more in the chance as opposed to the baseline condition, while for high-skill participants the opposite is true. For example, for a participant who ranked 12th, the probability of entry was 0.37 in the baseline but 0.56 in the chance condition. For a participant ranked first, the analogous probabilities were 0.95 and 0.92 .

This result confirms our hypotheses that the effect of augmented chance on entry is asymmetric with respect to skill. However, the effect of chance is weaker for highskill participants. They are not so sensitive to the increased level of uncertainty. To further compare the sensitivity of high- and low-skill participants to increasing uncertainty, we estimated logit models of entry, analogous to model 3, separately for high and low-skill participants. We split participants by their median performance classifying them as low-skill if they ranked 8 or worse and as high-skill otherwise ${ }^{6}$. Table 3 reports the results of these models.

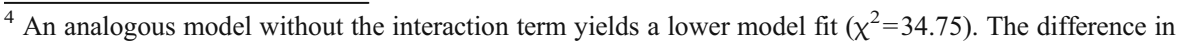
fit is statistically significant $(p=0.002)$.

${ }^{5}$ Plots of the predicted probabilities obtained from models $2-5$ in Table 2 look similar to those presented in Fig. 3.

${ }^{6}$ We performed a similar analysis splitting participants in three groups: the best (rank between 1 and 5), medium (rank between 6 and 10), and the worst performance (rank between 11 and 15). This procedure yielded coefficients of "chance" of similar magnitudes for the best and the worst participants.
} 


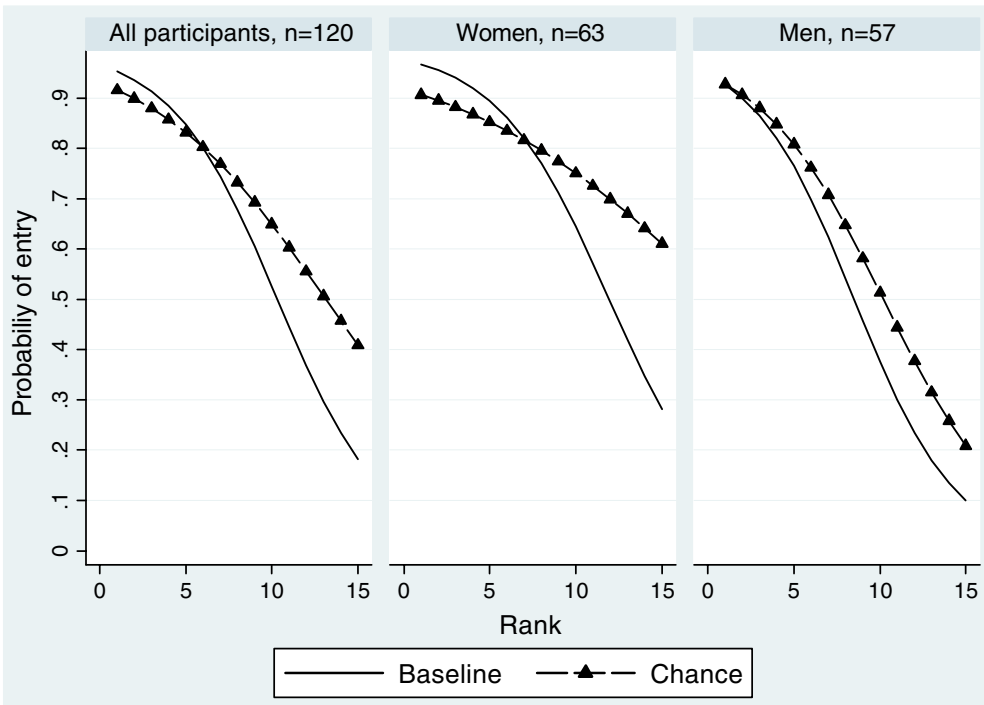

Note: Plots are based on the results presented in Tables 2 (model 3) and 6. The probability of entry includes the main effect of chance ( 0 for the baseline and 1 for the chance condition), the intercept between chance and skill, and the effects of all other variables included in the models (estimated at their mean levels); random effects $u_{i}$ are assumed to be 0 .

Fig. 3 Plot of the effects of skill on the probability of entry

In line with the plots in Fig. 3, the effect of the indicator variable "chance" is positive for high-skill participants and negative for low-skill participants. The magnitude of the effect of chance is much smaller for the former than for the latter. In particular, consistent with Hypothesis 1, entry rates of low-skill participants are 17.2 percentage points higher in the chance as compared to the baseline condition (logit coefficient of 0.730$)$. The effect is significantly different from zero $(p<0.001)$. For high-skill participants, entry rates are 3.0 percentage points lower in the chance as compared to the baseline condition (logit coefficient of -0.298). The direction of the effect is consistent with Hypothesis 2. However, the evidence supporting this hypothesis is weak: the effect of chance on the behavior of high-skilled individuals is not statistically significant.

Parenthetically, descriptive data are consistent with the results of the logit models. On average, participants with the worse rankings (8th or worse) entered the market in 2.5 baseline rounds and 3.3 chance rounds (both out of six). Participants with the better rankings ( 7 th or better) entered the market in, on average, 4.6 baseline rounds and 4.5 chance rounds. In short, chance induced the poorer but not the better performers to enter the competition more. The outcomes of chance, however, were generally not positive. Mean losses of the less skilled participants (8th or worse) were approximately the same in the baseline and chance rounds: $3.82 €$ and $3.43 €$ (statistically, an insignificant difference, $z=-1.35, n=63$, Wilcoxon signed-rank test). However, the higher ranked participants (7th or better) gained less in the chance than in the baseline rounds: $0.83 €$ vs. 2.41€ $(p<0.001, z=3.35, n=57$, Wilcoxon signed-rank test). 
Table 3 Logit models of entry, by skill level

\begin{tabular}{lcc}
\hline & High skill & Low skill \\
\hline Chance $(0 / 1)$ & $-0.298(0.340)$ & $0.730 * * *(0.208)$ \\
Rank & $-0.557 * * *(0.164)$ & $0.030(0.107)$ \\
Big chance $(0 / 1)$ & $-0.514(0.628)$ & $0.031(0.432)$ \\
Order $(0 / 1)$ & $0.533(0.649)$ & $0.343(0.450)$ \\
Female $(0 / 1)$ & $0.616(0.643)$ & $0.592(0.485)$ \\
IE score & $0.019(0.077)$ & $0.100(0.071)$ \\
Forecasted number of entrants & $0.115(0.072)$ & $0.099(0.053)$ \\
Constant & $2.919 *(1.344)$ & $-3.431 *(1.456)$ \\
$\sigma_{\mathrm{u}}$ & $1.994 * *(0.325)$ & $1.550 * * *(0.215)$ \\
Model $\chi^{2}$ & 19.58 & 28.14 \\
Number of observations & 684 & 756 \\
Number of participants & 57 & 63 \\
\hline
\end{tabular}

Dependent variable $=$ Entry $(0 / 1)$

Random-effect models were fitted

High-skill individuals are ranked 7 or better

Low-skill individuals are ranked 8 or worse

Robust standard errors, adjusted for clustering on individuals, are in parentheses

$* * * p<0.001, * * p<0.01, * p<0.05$

The effects of several additional covariates in the models presented in Table 2 are worth mentioning. First, the effects of two lagged variables - entry decision made in the previous round and the payoff earned in that round (models 4 and 5) - are positive and significant which implies that positive feedback from previous entry increased the probability of entry in a given round. The effect of lagged payoff differed in the baseline and chance rounds. Models, analogous to model 4, fit separately on the data from the baseline and chance conditions (the logit specifications are not presented here) showed that in the baseline conditions, earning more in a given round increases the probability of entry in the subsequent round (logit coefficient of 0.187 , robust $\mathrm{se}=0.036, p<0.001$ ). In the chance condition, the effect of lagged payoff was not significant (logit coefficient of 0.001 , robust $\mathrm{se}=0.031$, ns). This implies that participants correctly understood that past performance in the competition was less predictive of future performance in the chance as opposed to baseline rounds.

Second, the indicator variable "big chance" is not significant in any of the models presented. There is no evidence that increasing the level of the additional uncertainty (a between-subject manipulation) affected behavior.

Finally, the logit specifications fail to show any consistent statistically significant difference in the probability of entry for participants of different gender, with different IE-scores, and who forecast more vs. less entrants in experimental rounds. 


\subsection{Excess entry}

The data reveal "excess entry" in that there were between six and fourteen entrants each round (40\%-93\% of all participants). (Recall market capacity was five entrants). Figure 4 shows the actual number of entrants in each session and the mean number of entrants predicted by participants at the beginning of each experimental round. As a reference point, we have added horizontal lines corresponding to the mixed-strategy equilibrium prediction of 7.9 entrants (assuming risk-neutrality and no private information about relative performance on the test).

Figure 4 shows that of the eight sessions, it was only in one that the number of entrants in the first round-for which the equilibrium benchmark is most appropriate - was close to the equilibrium prediction of 7.9 players. Nevertheless, the decreasing slope of entry curves in Fig. 4 suggests some learning from performance feedback.

A surprising finding is the relative accuracy with which participants anticipated the number of entrants. There was no consistent tendency to over- or underestimate the number of entrants. Across all rounds, the difference between the predicted and actual number of entrants was, on average, 0.1 persons, and the mean absolute difference was 2.0 persons. There was no significant difference between the baseline and chance rounds in terms of the magnitude of the prediction errors.
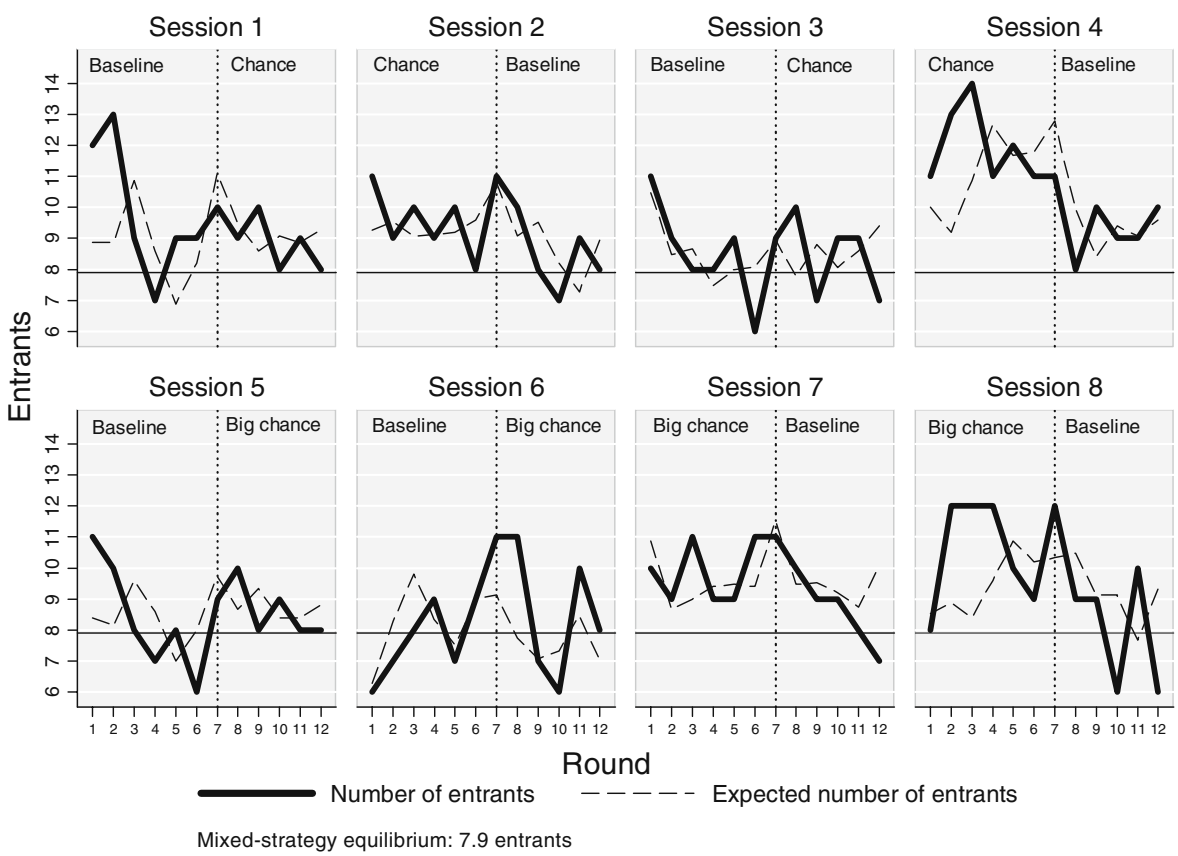

Expected number of entrants

Note: There were 15 participants in each session.

Fig. 4 Entry by session and round 


\subsection{Confidence in test performance}

Participants were better at estimating their score (i.e., absolute "skill") than their rank (i.e., comparative "skill"). Of the 120 participants, 43 correctly estimated their score and only 11 correctly estimated their rank. The correlation between actual and estimated scores was 0.67 (Spearman's rank correlation, $p<0.001, n=120$ ); the correlation between actual and estimated rank was 0.40 (Spearman's rank correlation, $p<0.001, n=120$ ). Moreover, estimated score was a better predictor of actual rank (i.e., the criterion relevant to entry decision) than estimated rank (Spearman's rank correlation of $-0.62, p<0.001, n=120)$. Overall, participants' estimates of their scores and ranks were imperfect.

To quantify overconfidence and underconfidence, we defined confidence about score as estimated score minus actual score and confidence about rank as estimated rank minus actual rank. Positive values indicate overconfidence, negative imply underconfidence. Of the 120 participants, 58 were overconfident about their score and 19 were underconfident. As to confidence about ranks, 70 were overconfident and 39 were underconfident. Figure 5 depicts mean confidence for different performance levels. The upper panel shows that participants who solved more problems correctly on the test were less overconfident, on average, than those who solved less. The lower panel shows that participants who ranked among the best five were on average underconfident about their rank, while participants who ranked worse were on average overconfident.

Note that participants estimated their performance in the test before the market entry game. The decreasing slopes of the entry curve in Fig. 4 suggest that these initial estimates were refined during the market entry game as participants received feedback. Indeed, as reported above, the probability of entry in a given round was higher when the payoff from the previous round was larger. Thus, confidence in skill elicited before the market entry game can only be taken to represent an initial level of confidence rather than a characteristic that was stable during all experimental rounds.

With this caution in mind, we investigated whether initial confidence affected entry decisions. We included confidence variables in the logit specifications presented in Table 2-model 5. Our interest was to understand whether, given the same level of performance in the tests, greater initial confidence implied higher probability of entry. For this purpose, we additionally control for actual score and rank. The effects of neither confidence about score nor confidence about rank are significant in this specification, and the marginal effects of these variables are virtually null (not reported here). There is insufficient evidence to conclude that the initial level of confidence affected entry decisions. ${ }^{7}$

\subsection{Gender effects in confidence and entry}

Men were more confident about their performance in the test than women. Table 4 details the proportions of underconfident, overconfident, and well-

\footnotetext{
${ }^{7}$ Initial confidence did not affect entry decision in the first round either. A logit model of entry that was fit on the data from the first rounds and included estimated and actual score and rank as independent variables, yielded no significant coefficients.
} 

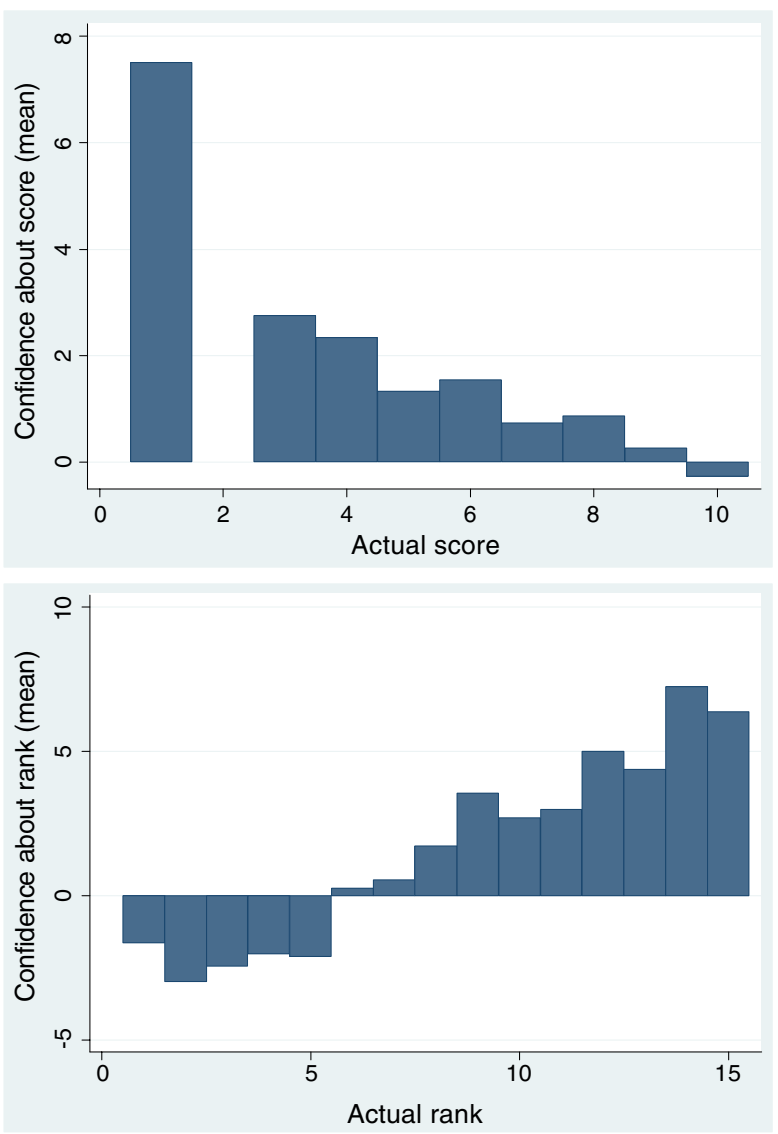

Note: Confidence about score (upper panel) $=$ estimated score - actual score Confidence about rank (lower panel) $=$ estimated rank - actual rank

Fig. 5 Confidence about performance in the test

calibrated (i.e., estimates equal to actual values) male and female participants as well as mean confidence within each group. While the details on confidence about test score look similar for men and women (most of them slightly overestimating their score, a few underestimating), women who underestimate their rank do so much more than men (mean underestimation of 3.7 vs. 2.2 positions in the ranking). ${ }^{8}$ There was no gender difference in actual ranks (means of 8 for women and men, $z=0.77, n s, n=120$, Wilcoxon rank-sum test). A linear regression model of estimated rank with an indicator female as independent variable and actual rank as control yielded a coefficient of 2.1 for female (robust se $=0.49, p<0.001, n=120$,

\footnotetext{
${ }^{8}$ Overall, the gender difference in confidence about scores was not statistically significant $(z=0.94$, $n=120$, Wilcoxon rank-sum test), while the difference in confidence regarding placement in the ranking was significant ( $p<0.01, z=2.95, n=120$, Wilcoxon rank-sum test).
} 
Table 4 Confidence about performance in the test

\begin{tabular}{|c|c|c|c|c|c|c|}
\hline & \multicolumn{2}{|c|}{ Men } & \multicolumn{2}{|c|}{ Women } & \multicolumn{2}{|l|}{ Total } \\
\hline & $\mathrm{n}$ & Mean confidence & $\mathrm{n}$ & Mean confidence & $\mathrm{n}$ & Mean confidence \\
\hline \multicolumn{7}{|l|}{ Score } \\
\hline Overconfident & 30 & 1.8 & 28 & 1.7 & 58 & 1.8 \\
\hline Underconfident & 9 & -1.0 & 10 & -1.5 & 19 & -1.3 \\
\hline Well-calibrated & 18 & & 25 & & 43 & \\
\hline Total & 57 & 0.8 & 63 & 0.5 & 120 & 0.7 \\
\hline \multicolumn{7}{|l|}{ Rank } \\
\hline Overconfident & 40 & 4.8 & 30 & 4.1 & 70 & 4.5 \\
\hline Underconfident & 12 & -2.2 & 27 & -3.7 & 39 & -3.3 \\
\hline Well-calibrated & 5 & & 6 & & 11 & \\
\hline Total & 57 & 2.9 & 63 & 0.3 & 120 & 1.6 \\
\hline
\end{tabular}

$\left.\mathrm{R}^{2}=0.26\right)$ suggesting that women were indeed less confident about their rank than men. ${ }^{9}$

As to the decision to enter competition, the specifications presented in Table 2 show that the probability of entry was not lower for women than for men. If anything, women were somewhat more likely to enter competition, as the positive effect of the indicator variable "female" suggests.

To investigate whether the interaction of chance and skill described above occurred among both male and female participants, we analyzed the probability of entry separately for men and women using specifications identical to model 3 presented in Table 2. The predicted probability of entry from these gender-specific logit models is plotted in the middle (women) and right (men) panels of Fig. 3. (See also Table 6 in the Appendix that details the results from the logit models). The gender-specific predicted probabilities mirror the general result in that the probability of entry for low-skill female and male participants (higher values of rank) is larger in the chance than baseline condition. As to high-skill participants, women tend to enter less with chance than without (a significant interaction of rank and chance) while there is no apparent difference between the chance and baseline conditions among high-skill male participants.

Since further splits of data (by skill, within gender) reduce sample size, we prefer caution in drawing inferences about the behavior of high-skill participants and thus

\footnotetext{
${ }^{9}$ The gender gap in relative confidence echoes the findings of Niederle and Vesterlund (2007). In their experiment, men and women performed equally well on a test, but women were more likely to underrate their relative performance: $75 \%$ of men thought they were best in their group (of four participants), while only $43 \%$ of women shared this belief. In Niederle and Vesterlund's experiment, higher overconfidence among men partially explained why men were more willing than women to select into a competitive environment.
} 
conclude that, if anything, the actions of high-skill participants were only modestly affected by chance (as models in Table 3 indicate, first column).

\subsection{Attributions, risk, and fairness}

To analyze the attribution of outcomes and the perception of risk and fairness, we compressed the responses elicited on $0-10$ scales into $0 / 1$ variables ( 0 for answers below 6 and 1 otherwise).

Participants experienced the chance rounds as riskier than the baseline rounds. In particular, $47 \%$ of participants believed that the baseline rounds were risky (answers 7 and above), while the chance rounds were found risky by $71 \%$ of participants $\left(\chi^{2}=14.46, p<0.001\right)$. This result can be considered a manipulation check that participants understood that payoffs were more unpredictable in the chance as opposed to baseline condition. Participants also correctly indicated that chance played a bigger role in big as opposed to small chance sessions. That is, $48 \%$ of participants indicated that chance has been quite decisive in the small chance sessions vs. $75 \%$ of participants in the big chance sessions $\left(\chi^{2}=9.02, p<0.01\right)$.

Attributions and perceived fairness in the chance rounds were affected by participants' earnings. First, players who earned less were more likely to attribute the result to chance than those who earned more. In particular, for those who in the postgame questionnaire admitted that chance had been quite decisive in determining outcomes, the mean loss in the chance rounds was $-2.10 €$, while for those who believed chance had not been that important the mean loss was $-0.34 € .^{10}$ Second, larger individual payoffs were considered as being "fairer." Specifically, those who reported that outcomes were quite fair earned, on average, 1.26€ across the chance rounds, while those who believed that outcomes were unfair lost, on average, $3.37 € .^{11}$

\section{General discussion}

Our experimental innovation involved introducing an explicit random element in ranking participants in the market entry paradigm. An analog in naturally occurring situations could be, say, uncertainty concerning a change in membership of a committee deciding on grant proposals or job applications. Consider also new product launches. An entrepreneur might well have a good sense of her domainspecific competence relative to competitors, but also be aware that unknowable consumer tastes could perturb the market ranking of potential entrants. Book publishing provides a further example. An author can have a good track record and rank highly among peers; but this does not guarantee that a new novel will be accepted by the public or critics.

In summary, our results provide evidence of excess entry that was exacerbated when participants learned that an additional source of uncertainty would affect their

\footnotetext{
${ }^{10} p<0.05, z=2.33$, Wilcoxon rank-sum test, $n=74$ ("chance has been decisive") and 46 (the opposite).

${ }^{11} p<0.001, z=-6.49$, Wilcoxon rank-sum test, $n=51$ ("outcomes are fair") and 69 (the opposite).
} 
ranking. Interestingly, the effects were moderated by how well participants scored in the evaluation procedure (i.e., the math test). Consistent with our first hypothesis, participants with lower scores were more likely to enter the competition when uncertainty increased (Result 1) but, contrary to our second hypothesis, the actions of higher scoring participants were only modestly affected by the additional uncertainty (Results 2 and 3).

Additional findings were no differences in entry decisions due to levels of additional uncertainty (i.e., big chance versus small chance), and whereas men were more overconfident than women, they did not enter the competition more than women. Contrary to the claims of Camerer and Lovallo (1999), we found no relation between overconfidence and excess entry. Moreover, in post-round questionnaire responses participants recognized that chance rounds were riskier than their baseline counterparts. On the other hand, there was evidence of a self-serving bias in that participants who earned less money in the chance rounds were more likely to attribute their outcomes to chance than those who earned more.

We can view our results from different perspectives. One is from the viewpoint of studies that have looked at how, when skill is involved, increasing levels of uncertainty affect risk taking. Heath and Tversky (1991), for example, suggested a competence hypothesis whereby people who feel competent in a domain prefer to bet on ambiguous gambles in that domain over equiprobable known gambles-a form of ambiguity seeking (see also Tversky and Fox 1995; de Lara Resende and $\mathrm{Wu}$ 2010). That is, feelings of competence lead to seeking more risk as uncertainty - specifically ambiguity about outcomes-increases. Our results, however, are not entirely compatible with this explanation.

On the one hand, since the median score on the ranking test was high (9 out of 10), it could be argued that most participants felt competent at the task and therefore (following Heath and Tversky) would be inclined to take more risk as uncertainty increased. On the other hand, our situation differs from that studied by Heath and Tversky (1991) in two important ways. First, it is the less skilledor competent-who are more affected by uncertainty. And second, there is a confound in that, given the competitive nature of the market entry game, for lowly ranked players the probabilities of success do increase with the level of uncertainty. It is thus rational for the lowly-ranked players to increase their level of risk taking (although not to the level observed).

A second perspective for viewing our results concerns many studies that have considered the difficulties people experience in understanding the relative roles of skill and uncertainty in action-oriented tasks. This has a long history. For instance, in a series of innovative studies, Cohen and his colleagues investigated bus drivers' attempts to make tight maneuvers (Cohen et al. 1956), soccer players' shots at goal (Cohen and Dearnaley 1962), and success at hitting dart boards (Cohen and Hansel 1959). (See also Langer 1975.) The general finding is that for events that are difficult (low probability of success), the existence of a skill component leads to overestimating the probability of success. Interestingly, Atkinson (1957) found that when choosing between skill-related tasks of different difficulty levels, people motivated to achieve success as opposed to avoid failure tend to select tasks that are intermediate in difficulty (i.e., avoiding being almost sure to succeed or fail). 
Greater risk taking in the presence of both skill and increased uncertainty can also be seen as consistent with concerns about maintaining positive self-image when tested by skill-sensitive tasks (Larrick 1993; Köszegi 2006). In the case of success, self-image is enhanced. In the case of failure, uncertainty (i.e., bad luck) can be blamed for doing worse than expected. Therefore, it is possible to argue that more entry would be observed when outcomes depend on skill in the presence of greater uncertainty. In fact - and as noted above - the participants who earned less money in our market entry game when both chance and skill determined their performance were more likely to attribute the result to chance. This result is also consistent with the literature on self-attribution bias (Miller and Ross 1975).

Overall, our participants took too much risk and, as a result, their payoffs were lower than could have been achieved by participating less in the competition. In addition, although there was evidence of some learning through repeated experience, this did not eliminate excess entry. At the same time, our participants seemed to understand correctly that past performance is less predictive of future performance when uncertainty plays a larger role.

In our market entry game, confidence in own performance (measured at the beginning of the game) did not affect entry decisions. What we observed resembled imperfect self-selection into the game based on skill (i.e., test performance). (For a theoretical model of entry illustrating such self-selection, see Hogarth and Karelaia 2009). In addition, men were more confident than women in their performance (see also Lenney 1977; Barber and Odean 2001). And yet, men did not compete with other participants overall relatively more often than women, contrary to findings of Niederle and Vesterlund (2007) which showed men entering a competitive tournament more than women for any performance level. Why might these findings differ? First, although Niederle and Vesterlund also used a math test to measure performance and confidence, their participants took decisions in tournaments that differed from our experimental task. Second, whereas decisions in our experiment were made in semiprivate cubicles, Niederle and Vesterlund's participants were involved in a more faceto-face situation that could have had an impact. It is also possible that in our (mostly undergraduate) sample, women were, on average, used to performing academically as well as men and thus did not take less risk in a task related to performance.

Our investigation poses an intriguing puzzle. Our respondents were remarkably accurate at predicting the number of participants entering each round (across all conditions). At the same time, they only overplaced their ranking on average by one position. Why then did they enter markets where the most likely gain was $5 €$ but the cost of being wrong was $10 €$ ? In both the baseline and chance condition, there was excess entry in that mean profits were negative each round. There seemed to have been a pervasive overoptimism or "myopic self-focus" (Moore et al. 2007) that was only marginally affected by learning.

In summary, we augmented the realism of the market entry paradigm by including an explicit random component in determining payoffs and found that people take more risk when both skill and uncertainty, as opposed to skill alone, determine payoffs. Our data support the explanation that for people who assess their own skill as low, greater uncertainty induces more risk taking. Although not entirely "rational," the reason, we suggest, is not unreasonable. People with low skill know they cannot succeed if outcomes only depend on skill. Uncertainty is their only path 
to success even though, on average, by taking action most will fail. On the other hand, people who assess their skill as high still hope that this will ensure good outcomes whatever the role of uncertainty.

\section{Appendix}

Equilibrium entry predictions

Assuming risk neutrality and no private information about the probability of success on entry, there are multiple pure-strategy Nash equilibria with seven players $(47 \%)$ entering a market that has a capacity of five. At equilibrium, participants do not expect to receive a larger payoff by changing their strategy, i.e., by entering if the decision was to stay out and staying out if the decision was to enter. In our game, when there are fewer than seven entrants, a participant who stayed out could have received a positive payoff by entering, and with more than seven entrants, a participant who entered could have avoided an expected loss by staying out. In particular, the expected payoff of each of seven entrants is $\frac{5}{7} \frac{25 €}{5}+\frac{2}{7}(-10 €) \approx 0.71 €$. If there are eight entrants, the individual expected payoff is $\frac{5}{8} \frac{25 €}{5}+\frac{3}{8}(-10 €) \approx-0.63 €$. Expected payoffs for all numbers of entrants are detailed in Table 5 (lower panel, first column).

Provided that players cannot coordinate, there is a mixed-strategy equilibrium in which each risk-neutral player (without private information about the probability of success on entry) enters with a probability $p$. The value of $p$ is found by equating the expected payoff of entry and the payoff of staying out (see also Rapoport et al. 1998):

$\sum_{E=1}^{5}\left(\begin{array}{c}15 \\ E\end{array}\right) p^{E}(1-p)^{15-E} \frac{25 €}{E}+\sum_{E=6}^{15}\left(\begin{array}{c}15 \\ E\end{array}\right) p^{E}(1-p)^{15-E}\left[\frac{5}{E} \frac{25 €}{5}+\left(1-\frac{5}{E}\right)(-10 €)\right]=0$. In this game, each player enters with probability $p$ of $53 \%$. That is, 7.9 players (out of 15) will enter on average each round (Table 5, lower panel, first column).

If all players know their relative performance on the test, then clearly only the top five players (33\% of all potential entrants) will enter. However, if players have imperfect information about their test performance, it is instructive to speculate how they might take account of competitors when assessing relative performance. Considerable evidence suggests that people tend focus on themselves and neglect others, thereby adopting a so-called "inside view" (Kahneman and Lovallo 1993; Camerer and Lovallo 1999; Kruger 1999; Moore et al. 2007). Thus, imperfect information about test performance could imply biased subjective estimates of probabilities of success. For example, assume that this bias is captured by a parameter $\alpha(-1>\alpha>1)$ that adjusts the probability of success on entry. Then, a player's (biased) expected payoff of entry when there are $E$ entrants $(E>5)$ is $(1+\alpha) \frac{5}{E} \frac{25 €}{5}+\left(1-(1+\alpha) \frac{5}{E}\right)(-10 €)$. Table 5 provides equilibrium results for $\alpha \neq 0$. For example, if $\alpha=0.2$, pure-strategy Nash equilibria occur when nine players (60\%) enter the market, and if $\alpha=-0.2$ six players (40\%) enter. In terms of mixed strategies, if $\alpha=0.2$ the equilibrium probability of entry is $62 \%$ (9.3 entrants), and if $\alpha=-0.2$ it is $46 \%$ (6.9 entrants). 
Table 5 Equilibrium analysis PURE-STRATEGY EQUILIBRIUM

Expected payoff, $€$

\begin{tabular}{rrccccc|}
\multicolumn{5}{c}{ Number of entrants } & \multicolumn{5}{c}{ alpha* } \\
\cline { 2 - 7 } & 1 & 25.00 & 25.00 & 25.00 & 25.00 & 25.00 \\
2 & 12.50 & 12.50 & 12.50 & 12.50 & 12.50 \\
3 & 8.33 & 8.33 & 8.33 & 8.33 & 8.33 \\
4 & 6.25 & 6.25 & 6.25 & 6.25 & 6.25 \\
5 & 5.00 & $\mathbf{5 . 0 0}$ & 5.00 & 5.00 & 5.00 \\
6 & 2.50 & -2.50 & $\mathbf{0 . 0 0}$ & 5.00 & 7.50 \\
7 & $\mathbf{0 . 7 1}$ & -3.57 & -1.43 & 2.86 & 5.00 \\
8 & -0.63 & -4.38 & -2.50 & 1.25 & 3.13 \\
9 & -1.67 & -5.00 & -3.33 & $\mathbf{0 . 0 0}$ & 1.67 \\
10 & -2.50 & -5.50 & -4.00 & -1.00 & $\mathbf{0 . 5 0}$ \\
11 & -3.18 & -5.91 & -4.55 & -1.82 & -0.45 \\
12 & -3.75 & -6.25 & -5.00 & -2.50 & -1.25 \\
13 & -4.23 & -6.54 & -5.38 & -3.08 & -1.92 \\
14 & -4.64 & -6.79 & -5.71 & -3.57 & -2.50 \\
15 & -5.00 & -7.00 & -6.00 & -4.00 & -3.00 \\
\hline
\end{tabular}

MIXED-STRATEGY EQUILIBRIUM

Expected payoff, $€$

\begin{tabular}{|c|c|c|c|c|c|}
\hline \multirow[b]{2}{*}{ Number of entrants } & \multicolumn{5}{|c|}{ alpha } \\
\hline & 0 & -0.4 & -0.2 & 0.2 & 0.4 \\
\hline 1 & 0.01 & 0.09 & 0.03 & 0.00 & 0.00 \\
\hline 2 & 0.02 & 0.22 & 0.10 & 0.00 & 0.00 \\
\hline 3 & 0.07 & 0.45 & 0.23 & 0.01 & 0.00 \\
\hline 4 & 0.17 & 0.71 & 0.44 & 0.03 & 0.00 \\
\hline 5 & 0.33 & 0.88 & 0.66 & 0.08 & 0.01 \\
\hline 6 & 0.31 & -0.51 & 0.00 & 0.22 & 0.06 \\
\hline 7 & 0.13 & -0.66 & -0.29 & 0.27 & 0.12 \\
\hline 8 & -0.13 & -0.57 & -0.43 & 0.20 & 0.20 \\
\hline 9 & -0.30 & -0.36 & -0.38 & 0.00 & 0.21 \\
\hline 10 & -0.30 & -0.17 & -0.23 & -0.20 & 0.10 \\
\hline 11 & -0.19 & -0.06 & -0.10 & -0.28 & -0.10 \\
\hline 12 & -0.09 & -0.01 & -0.03 & -0.21 & -0.24 \\
\hline 13 & -0.03 & 0.00 & -0.01 & -0.10 & -0.22 \\
\hline 14 & 0.00 & 0.00 & 0.00 & -0.03 & -0.11 \\
\hline 15 & 0.00 & 0.00 & 0.00 & 0.00 & -0.02 \\
\hline sum & 0.00 & 0.00 & 0.00 & 0.00 & 0.00 \\
\hline Probability of entry & 0.53 & 0.41 & 0.46 & 0.62 & 0.72 \\
\hline Number of entrants & 7.9 & 6.2 & 6.9 & 9.3 & 10.8 \\
\hline Group profit**, $€$ & -4.4 & 13.1 & 6.2 & -18.5 & -33.0 \\
\hline
\end{tabular}

Notes: * alpha is an adjustment coefficient of the subjective probability of success on entry.

$* *=25 €$ if 5 or fewer enter; $25 €-10 € *(\mathrm{E}-5)$ if $\mathrm{E}>5$ enter. 
Table 6 Logit models of entry, by gender

\begin{tabular}{lcc}
\hline & Men & Women \\
\hline Chance $(0 / 1)$ & $-0.045(0.562)$ & $-1.268(0.691)$ \\
Rank & $-0.338^{* * *}(0.067)$ & $-0.307 * * *(0.093)$ \\
Rank*chance & $0.061(0.057)$ & $0.177 * *(0.067)$ \\
Big chance $(0 / 1)$ & $0.505(0.456)$ & $-0.840(0.594)$ \\
Order $(0 / 1)$ & $0.041(0.470)$ & $0.888(0.588)$ \\
IE score & $0.062(0.065)$ & $0.048(0.088)$ \\
Forecasted number of entrants & $0.160 * *(0.059)$ & $0.036(0.055)$ \\
Constant & $0.542(1.093)$ & $2.757 *(1.219)$ \\
$\sigma_{\mathrm{u}}$ & $1.538^{* * *}(0.279)$ & $2.009 * * *(0.275)$ \\
Model $\chi^{2}$ & 41.73 & 25.40 \\
Number of observations & 684 & 756 \\
Number of participants & 57 & 63
\end{tabular}

Dependent variable $=$ Entry $(0 / 1)$.

Random-effect models were fitted.

Robust standard errors, adjusted for clustering on individuals, are in parentheses.

$* * * p<0.001, * * p<0.01, * p<0.05$

\section{References}

Atkinson, J. W. (1957). Motivational determinants of risk-taking behavior. Psychological Review, 64, 359372 .

Barber, B., \& Odean, T. (2001). Boys will be boys: gender, overconfidence, and common stock investment. Quarterly Journal of Economics, 116(1), 261-292.

Benoît, J.-P., \& Dubra, J. (2009). Overconfidence? Unpublished working paper, London Business School and Universidad de Montevideo.

Byrnes, J. P., Miller, D. C., \& Schafer, W. D. (1999). Gender differences in risk taking: a meta-analysis. Psychological Bulletin, 125(3), 367-383.

Camerer, C. F., \& Lovallo, D. (1999). Overconfidence and excess entry: an experimental approach. American Economic Review, 89(1), 306-318.

Chevalier, J., \& Ellison, G. (1997). Risk taking by mutual funds as a response to incentives. Journal of Political Economy, 105(6), 1167-1200.

Cohen, J., \& Hansel, M. (1959). Preferences for different combinations of chance and skill in gambling. Nature, 183, 841-843.

Cohen, J., \& Dearnaley, E. (1962). Skill and judgment of footballers in attempting to score goals: a study of psychological probability. British Journal of Psychology, 53, 71-86.

Cohen, J., Dearnaley, E. J., \& Hansel, C. E. M. (1956). Risk and hazard: influence of training on the performance of bus drivers. Journal of the Operational Research Society, 7, 67-82.

Croson, R., \& Gneezy, U. (2009). Gender differences in preferences. Journal of Economic Literature, 47 (2), 448-474.

de Lara Resende, J. G., \& Wu, G. (2010). Competence effects for choices involving gains and losses. Journal of Risk and Uncertainty, 40, 109-132.

Degeorge, F., Moselle, B., \& Zeckhauser, R. (2004). The ecology of risk taking. Journal of Risk and Uncertainty, 28(3), 195-215.

Fischbacher, U. (1999). Ztree: A toolbox for readymade economic experiments. Working Paper, Institute For Empirical Research In Economics, University of Zurich. 
Gaba, A., \& Kalra, A. (1999). Risk behavior in response to quotas and contests. Marketing Science, 18(3), $417-434$

Gaba, A., Tsetlin, I., \& Winkler, R. (2004). Modifying variability and correlation in winner-take-all contests. Operations Research, 52(3), 384-395.

Grieco, D., \& Hogarth, R. M. (2009). Overconfidence in absolute and relative performance: the regression hypothesis and Bayesian updating. Journal of Economic Psychology, 30, 756-771.

Heath, C., \& Tversky, A. (1991). Preference and belief: ambiguity and competence in choice under uncertainty. Journal of Risk and Uncertainty, 4, 5-28.

Hogarth, R. M., \& Karelaia, N. (2009). Entrepreneurial success and failure: Confidence and fallible judgment. Working Paper, Universitat Pompeu Fabra, Barcelona.

Kahneman, D., \& Lovallo, D. (1993). Timid choices and bold forecasts: a cognitive perspective on risk taking. Management Science, 39(1), 17-31.

Köszegi, B. (2006). Ego utility, overconfidence, and task choice. Journal of the European Economic Association, 4(4), 673-707.

Kruger, J. (1999). Lake Wobegon be gone! The "below-average effect" and the egocentric nature of comparative ability judgments. Journal of Personality and Social Psychology, 77(2), 221-232.

Langer, E. J. (1975). The illusion of control. Journal of Personality and Social Psychology, 32(2), 311-328.

Larrick, R. P. (1993). Motivational factors in decision theories: the role of self-protection. Psychological Bulletin, 113, 440-450.

Lenney, E. (1977). Women's self-confidence in achievement settings. Psychological Bulletin, 84, 1-13.

Miller, D. T., \& Ross, M. (1975). Self-serving biases in the attribution of causality: fact or fiction? Psychological Bulletin, 82, 213-225.

Moore, D. A., \& Cain, D. M. (2007). Overconfidence and underconfidence: when and why people underestimate (and overestimate) the competition. Organizational Behavior and Human Decision Processes, 103, 197-213.

Moore, D. A., \& Healy, P. J. (2008). The trouble with overconfidence. Psychological Review, 115 (2), 502-517.

Moore, D. A., Oesch, J. M., \& Zietsma, C. (2007). What competition? Myopic self-focus in market-entry decisions. Organization Science, 18(3), 440-454.

Niederle, M., \& Vesterlund, L. (2007). Do women shy away from competition? Do men compete too much? Quarterly Journal of Economics, 122(3), 1067-1101.

Rapoport, A., Seale, D., Erev, I., \& Sundali, J. (1998). Equilibrium play in large group market entry games. Management Science, 44(1), 119-141.

Rotter, J. B. (1966). Generalized expectancies for internal versus external control of reinforcements. Psychological Monographs, 80(1), 1-28.

Tsetlin, I., Gaba, A., \& Winkler, R. L. (2004). Strategic choice of variability in multiround contests and contests with handicaps. Journal of Risk and Uncertainty, 29(2), 143-158.

Tversky, A., \& Fox, C. R. (1995). Weighing risk and uncertainty. Psychological Review, 102, $269-283$. 